\title{
The results of experimental studies of VLF-ULF electromagnetic emission by rock samples due to mechanical action
}

\author{
A. A. Panfilov \\ North-East Interdisciplinary Science Research Institute n. a. N. A. Shilo, Far East Branch, Russian Academy of Sciences \\ (NEISRI FEB RAS), Magadan, Russia
}

Correspondence to: A. A. Panfilov (panfilov@ neisri.ru)

Received: 16 October 2013 - Published in Nat. Hazards Earth Syst. Sci. Discuss.: 23 December 2013

Revised: 4 April 2014 - Accepted: 22 April 2014 - Published: 2 June 2014

\begin{abstract}
The paper presents the results of laboratory experiments on electromagnetic emissions excitation (the electric component of electromagnetic fields) by rock samples due to different forms of mechanical stress applications. It was shown that samples generate electric impulses with different spectra when the impact action, gradual loading or dynamic friction is applied. It was ascertained that level and spectral compositions of signals, generated by rock samples, change with an increasing number of hits. It was found that strong electromagnetic signals, generated while rock samples were fracturing, were accompanied by repetitive weak but perceptible variations in the electric field intensity in short frequency ranges.
\end{abstract}

\section{Introduction}

It has been supposed that many earthquakes are accompanied by electromagnetic (EM) anomalies (Kopytenko et al., 1990; Molchanov et al., 1992; Hayakawa and Fujinawa, 1994; Nomikos et al., 1997; Lsaev et al., 2000; Eftaxias et al., 2003; Hayakawa et al., 2005; Ida et al., 2008). Many EM events, registered by different seismo-electromagnetic stations situated in different countries, can be related to the ionospheric perturbations located over seismoactive zones (Hayakawa, 1990; Liu et al., 2004; Rapoport et al., 2004), charged particles coming out of the Earth's interior (Carpinteri et al., 2012), water solutions flowing in the fracture area (Ishido and Mizutani, 1981), or various EM emission generation mechanisms (Nitsan, 1977; Vallianatos and Tzanis, 1998; Ogawa and Utada, 2000; Tzanis and Vallianatos, 2001) in hypocenters of earthquakes, so we cannot assert with confidence that the observed EM anomalies are of seismic origin (Masci, 2012a, b; Masci and Thomas, 2013).

The difficulty of studying the seismic-electromagnetic (SEM) precursor nature consists in the absence of a precise description of the processes that occur in the zones where the earthquakes are preparing. Also, a large number of technogeneous EM interferences makes detection of SEM signals complicated (Tzanis, et al., 2000). It is obvious that a process of earthquake initiation is accompanied by rock failure in the hypocenter. Different mechanoelectrical transformations can occur during initiation processes. Laboratory experiments show that rocks, even those that do not contain piezoelectric minerals, can generate EM emissions in a wide frequency range under mechanical stress, as well as pressurestimulated currents (Anastasiadis et al., 2007; Rabinovitch et al., 1998; Stavrakas et al., 2004; Freund, 2007; Triantis et al., 2007; Yasuhiko et al., 2009). We need to mention that, usually, published papers represent the results of experiments carried out with only one type of mechanical influence like loading, with the subsequent fracture of the samples or gradual loading without failure; impact; rubbing samples with, as a rule, smoothed surfaces.

A choice of VLF-ULF range for our research is associated with the distinctive features of a long EM wave propagation in different mediums. There is a possibility that some part of the ULF EM radiation generated in the hypocenter of the earthquake can reach the Earth's surface (Mognaschi, 2002). Also, we took into consideration the working frequency range (VLF) of the seismic-electromagnetic stations network situated in our region.

It is obvious that deformation, fracturing of rocks and formation of EM fields proceed during some amount of time, 
and, within this time, the spectral composition of EM emissions can change. To know the characteristics of the signal at different phases of its formation, we can use short-time Fourier transform or wavelet analysis as it was introduced by Kyriazis et al. (2006).

The purpose of our laboratory research was to determine the characteristic properties of electric emissions frequency and amplitude variations in VLF-ULF ranges during the dynamic action on rock samples.

The electrical component of EM signals generated by rock samples under the impact, gradual loading, and friction is considered in the current article. The recorded signals were analyzed by short-time Fourier transform.

\section{Experimental procedure}

Samples of quartz, granite, granodiorite, and shale were selected for our experiments. They were shaped as cubes with 2,3 , and $4 \mathrm{~cm}$ edges.

To prevent the influence of various EM interferences and natural noises on the registered signal, the experiment was conducted inside a steel box. To prevent a contact of metallic surface with a rock specimen and undesirable impact-caused vibrations, a sample was located on the massive plexiglas plate, which was placed on dense foam rubber. The receiving antenna was placed $25 \mathrm{~mm}$ away from a sample, which had piezo pickup attached to it. An antenna was connected to an amplifier with a selected band-pass filter of $20-30000 \mathrm{~Hz}$. The amplifier was linked to the L-761 analog-to-digital converter with a sample rate of $125 \mathrm{kHz}$. Power Graph 2.1 software with a sample rate set to $48 \mathrm{kHz}$ was used for recording. Monitoring was held in the $20-24000 \mathrm{~Hz}$ range. The diagram of the experimental setup is depicted on Fig. 1a. A $31.4 \mathrm{gm}$ steel ball, which was covered with a thin layer of rubber, served as a hummer. The distance of its fall was $243 \mathrm{~mm}$. Since the point of contact of the ball and a rock specimen was slightly varying, the experiment was held three times for each sample. Some samples were subjected to a greater number of hits (900 impacts) to evaluate the effect of such an action on characteristics of the generated EM signal. For the friction and gradual loading experiments, a laboratory press (P-50) with a maximum load of $500 \mathrm{kN}$ was used. The average loading velocity was $5.7 \times 10^{-4} \mathrm{~m} \mathrm{~s}^{-1}$. Rock samples $1 \mathrm{~cm}$ thick and with square sections $(4 \times 4 \mathrm{~cm})$ were subjected to the friction action. Taking into account that the probability of the existence of perfectly flat and smooth surfaces in natural conditions is extremely low, the rubbing faces of the samples were not ground. The rock plates were placed in the clamp, which was a vice with internal $1 \mathrm{~cm}$ plywood gaskets for preventing the contact of metal with a sample. Also, thin sheets of fiberboard were attached to the surfaces of the press metallic basses (Fig. 1b). The antenna was situated $1 \mathrm{~cm}$ away from a sample's surface. The recording of the signal was carried out via the sound card (frequency bandwidth $20-24000 \mathrm{~Hz}$ )

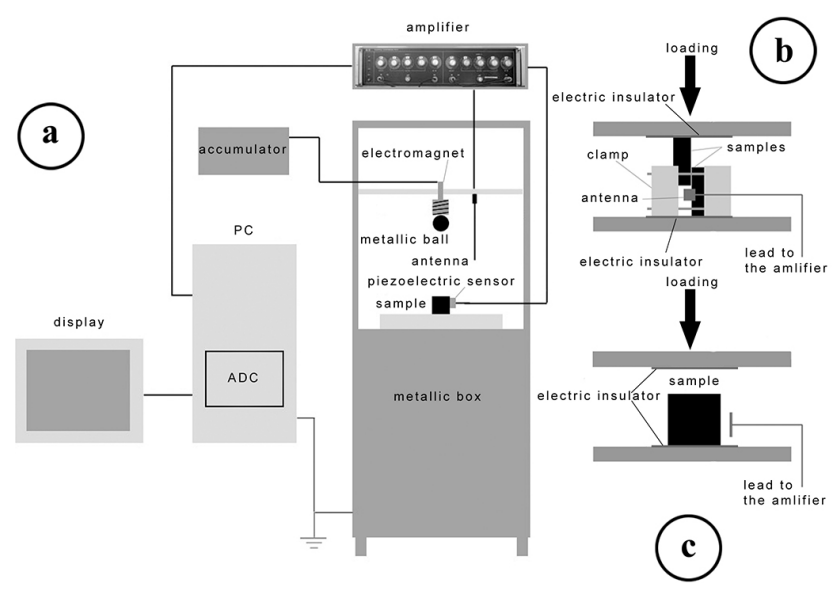

Figure 1. Diagram of the experimental setup. (a) Impact action on samples, (b) rubbing of two samples, (c) gradual loading.

and PowerGraph 2.1 software. Pairs of samples of equal rock types and a pair of samples of different rock types were used in the experiments.

The loading was applied till complete fracture of the samples. The diagram of the experimental setup is illustrated in Fig. 1c. Cubic-shaped specimens, with 3 and $4 \mathrm{~cm}$ faces, were placed between two thin fiberboard plates to insulate them eclectically from metallic bases of the press. The antenna was placed $1 \mathrm{~cm}$ away from the rock cube. Loading was raised at a constant rate.

A signal, received from the antenna, was amplified by $40 \mathrm{~dB}$ in each experiment.

A special program was created for the spectral-temporal analysis and for the spectrogram construction. It is based on the short-time Fourier transform that allows us to obtain characteristics of a signal's frequency and amplitude distribution in time. A Hanning window function with an optimum width of $32 \mathrm{~ms}$ was used for experiments with gradual loading; $5.325 \mathrm{~ms}$ - friction test; $1.331 \mathrm{~ms}$ - impact action.

\section{Results and discussion}

\subsection{Impact}

The EM signals, related both to a rock sample and the metal ball, were registered when the sample was hit. Before the experiment was carried out, the EM emission generated by the metal ball hitting a surface of the plate was registered. It helped to select a signal, related to the impact action on a test specimen only, when the analysis was implemented. The form and spectral composition of the EM impulse generated by the ball are depicted in Fig. 2. A level of the emission was 3-5 times lower in comparison with the impulses excited by the rock samples.

Figure 3 depicts the spectrograms of the EM impulses that were registered during the impact actions (no more than three 


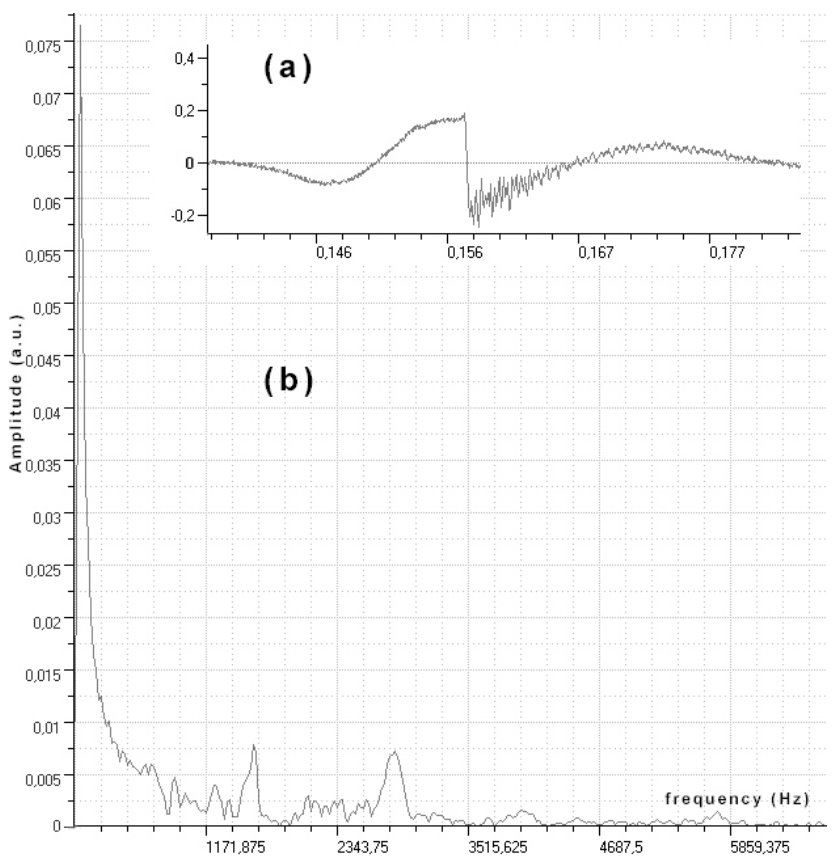

Figure 2. EM signal registered upon metal ball hit. (a) Amplitudetime representation, (b) spectra of the given signal.

hits) on the granite, granodiorite, quartz, and shale samples. In the tests with granite and granodiorite specimens, amplitudes of the recorded signals were located in the $0-6 \mathrm{kHz}$ frequency range - mainly at the bottom of the given band. During the impacts on the quartz samples, amplitudes of the EM emissions lay in the higher frequency band $(6-24 \mathrm{kHz})$.

Shale impacts resulted in an emissions amplitude mainly below $2 \mathrm{kHz}$. Only $5 \%$ of all samples were remarkable for the presence of the high-frequency components in the 8$21 \mathrm{kHz}$ band. Recordings of EM signals generated by the specimens that do not contain any piezoelectric materials are notable for the distinctly lower levels. On average, magnitudes of the EM emissions generated by granite, granodiorite and quartz samples were $50 \%$ higher than those generated by shale.

All samples subjected to impact action produced EM impulses that are notable for the abrupt increase in amplitude in the wide-frequency band, and following rapid decay in the area above $6 \mathrm{kHz}$ and gradual signal attenuation on the frequencies located below $6 \mathrm{kHz}$.

Samples that generated EM signals without pronounced high-frequency components were subjected to a higher number of hits. First impacts caused no significant changes in registered EM emissions. Their noticeable decay was observed after 100 hits (Fig. 4). After 300 impacts the experiment was interrupted. The second stage of impact action was carried out in $24 \mathrm{~h}$, and showed that the magnitudes of the signals were relatively close to their levels at the beginning of the experiment. The following decay was less rapid than during the

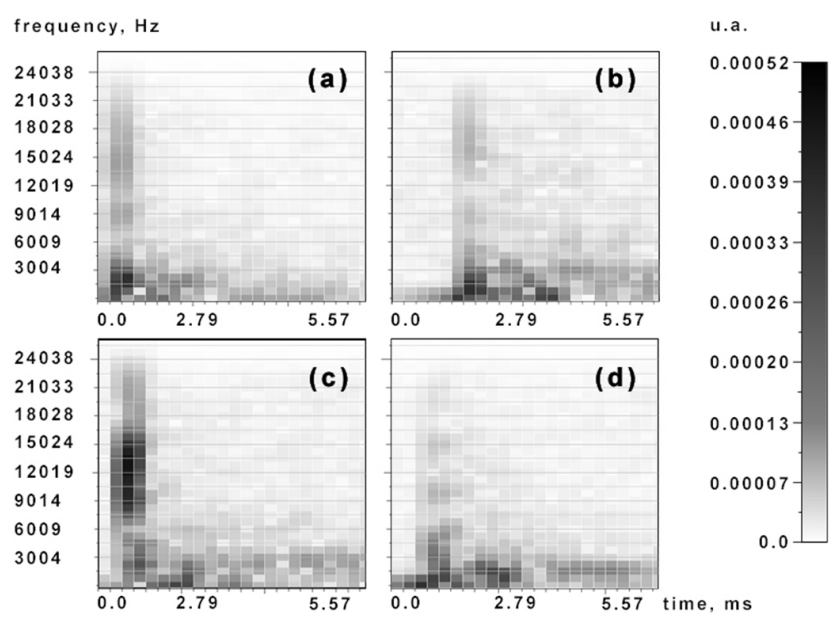

Figure 3. Spectrograms of the EM impulses resulting from impact action on (a) granite, (b) granodiorite, (c) quartz and (d) shale samples.

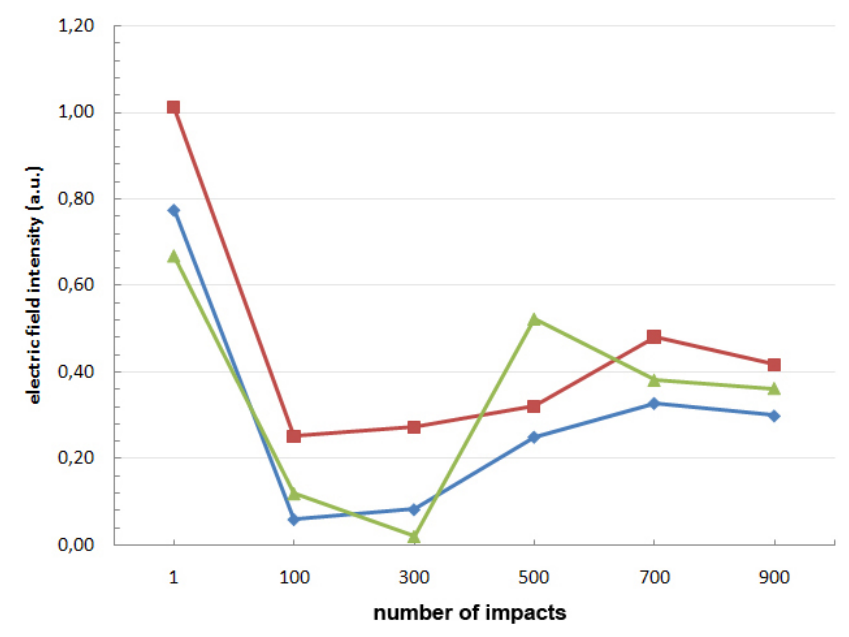

Figure 4. Decrease in the EM emissions magnitude during repeated impacts on shale (red), granite (green), and quartz (blue) samples.

first hundred hits. After 500 impacts a high-frequency component in the $2-3 \mathrm{kHz}$ band appears in the EM emissions, and its maximum magnitude in the $2-4.5 \mathrm{kHz}$ range is obtained by the 700th hit (Fig. 5). Damping of the signals then occurred at the frequencies lying higher than $2 \mathrm{kHz}$.

In general, the maximum signal amplitudes were located within the $0.25-1.5 \mathrm{kHz}$ range during the experiment.

\subsection{Gradual loading}

The strongest signal was observed during the quartz fracturing. Granite and granodiorite specimens are notable for the weaker emission, but some had no EM radiation. Usually, destruction of samples was accompanied by a set of EM impulses, with the largest number observed during fracturing of quartz samples with $4 \mathrm{~cm}$ faces. Granite and granodiorite 


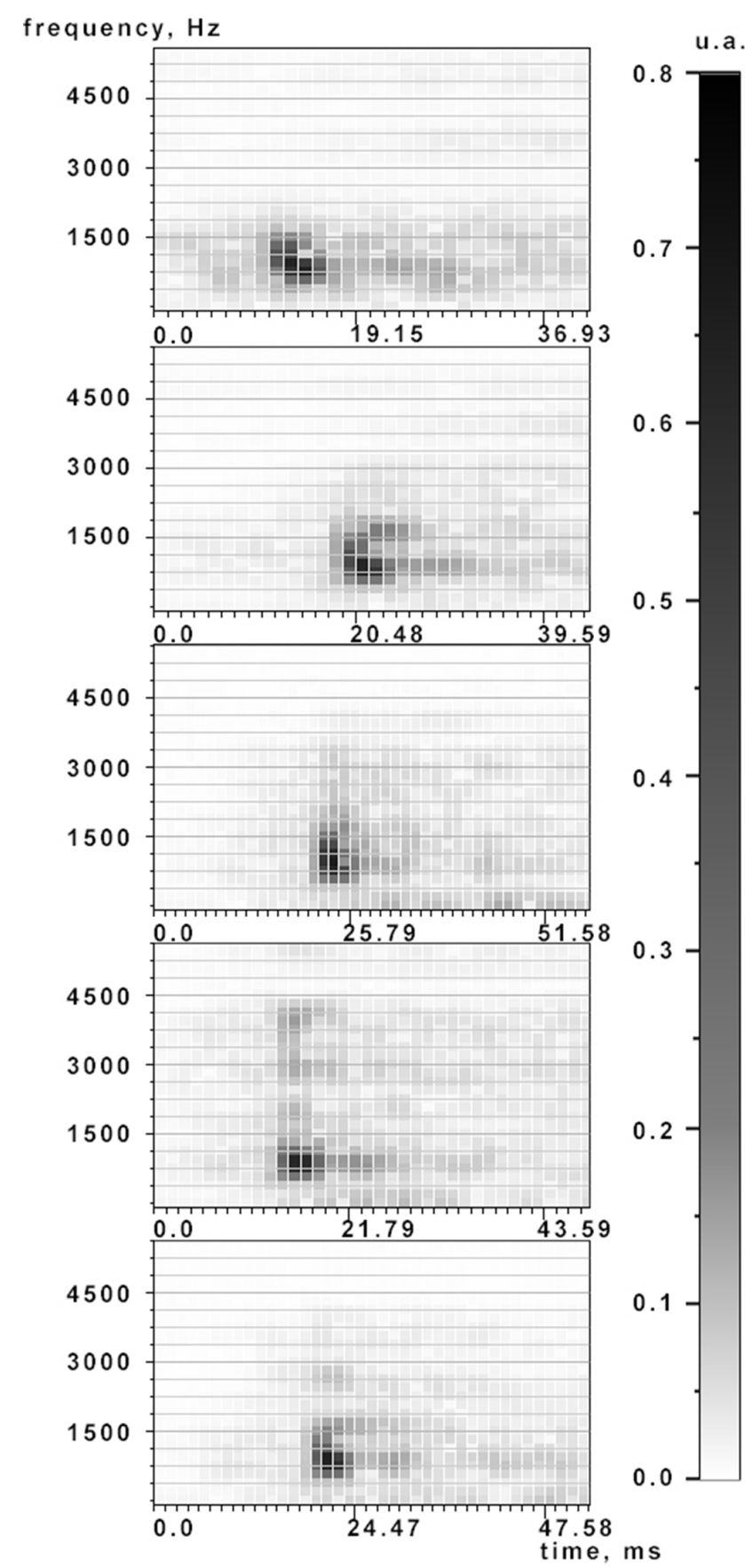

Figure 5. Spectrograms of the impulses after 100, 300, 500, and 900 impacts (from top to bottom).

specimens of the same dimensions had this number approximately six times lower. Samples with 3 and $2 \mathrm{~cm}$ faces have fewer EM impulses generated during the loading. Granite and granodiorite cubes with $3 \mathrm{~cm}$ faces differ from quartz samples of the same dimensions by a lower number of impulses. All specimens with $2 \mathrm{~cm}$ faces excite almost the same number of impulses (one or two). We found no correlation between the number of impulses and the type of rocks or

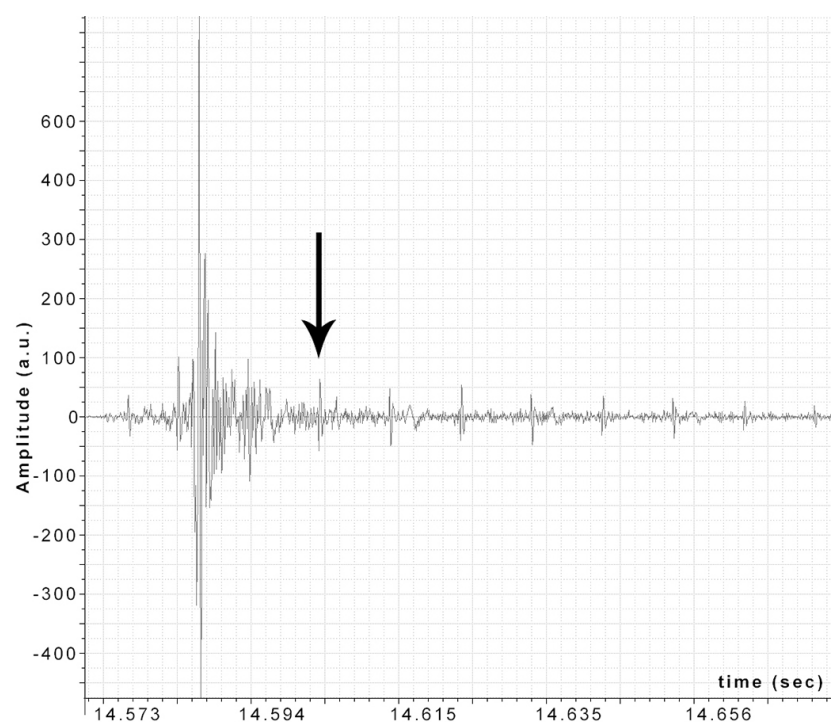

Figure 6. An EM signal registered during gradual loading of a granodiorite sample. The arrow points to one of the weak peaks that accompany the main impulse that is the strongest one.

sample dimensions. In a number of cases, EM signals consisted of adjacent pulse groups: the strongest impulse, and rows of weak equispaced pulses. One of the weak spikes is marked by the arrow in Fig. 6. It is obvious that such peaks appear before and after the strongest one. These spikes are located in the $0.5-2 \mathrm{kHz}$ frequency range; the pulse time is $1-2 \mathrm{~ms}$. It is shown by Nardi and Caputo (2009) that similar weak signals occurred during compression of samples. It is noted that orderly impulsive sequences (OIS) are "characterized by high frequency micro-impulses, which follow one another at regular intervals" (Nardi and Caputo, 2009). In comparison with our results, OISs lie in a higher frequency range and forerun strong disordered impulses. Also, they are localized within a short frequency band. In general, weak and ordered impulses that were registered by Nardi and Caputo (2009) and during our experiment seem to be of the same nature. Some distinctions in signal spectra can probably be explained by different sizes of rock samples and compression speeds that were used in both experiments.

In most cases, the formations of cracks in quartz were accompanied by the emission of a series of EM impulses in a short time interval of $10-30 \mathrm{~ms}$. Figure 7 depicts two weak signals that forerun the strongest one; the first impulse is the weakest one. In a few cases, low pulses appeared only after the strongest one. Apparently, all of these weak signals are located in wide frequency ranges that can be different for each rock sample.

Granodiorite specimens are notable for showing weak EM signals before and after some strong impulses during the gradual loading. Three of four samples generated EM impulses in the wide-frequency band $(0-5 \mathrm{kHz})$ and one did not emit any EM signals. 


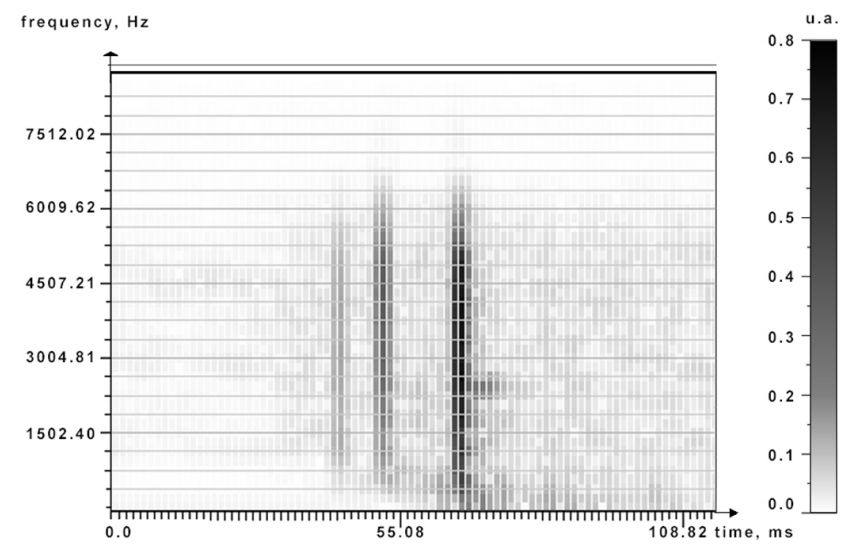

Figure 7. An EM signal registered during the quartz sample fracturing.

It was found that emissions intensity decreased when rock sample dimensions decreased. The weakest signals were emitted during fracturing of the cubes with $2 \mathrm{~cm}$ faces. The number of impulses was 1 or 2 (in rare instances 3 ). In this case, EM fields were usually located in a narrower frequency range than during the gradual loading of big samples. Such a situation is characteristic of all types of rocks used in our experiment.

\subsection{Friction}

For rock rubbing experiments, $1 \mathrm{~cm}$ thick plates with rough surfaces were used in consideration of an extremely low probability of perfectly flat surfaces in natural conditions. Friction of unground rocks causes local hitches to take place. With increased stress conditions deformation and subsequent fracturing can occur in these spots. Such processes are accompanied by abrupt breaking of the hitches and subsequent collisions of the asperities of rock sample surfaces. We assume that low-speed impacts take place there. It is obvious that such processes can accompany the shifts of rocks in natural conditions and that the characteristics of EM emission occurring in a given situation differ from the ones generated by the rocks with flat and smooth surfaces.

As follows from the conducted experiments, rock rubbing results in low-level EM signals emission. In the process of one sample slipping upon the surface of a second one, EM impulses were excited, and strong acoustic signals were observed. The generated EM radiation can be represented by one of three types: a short impulse (Fig. 9a), an impulse that is followed by a $10-30 \mathrm{~ms}$ emission in a narrow frequency range (Fig. 9b), and a noise-like signal (Fig. 8). Weak acoustic radiation is characteristic of a signal of the second type. We need to mention that, in some instances, the amplitudes of the impulses were extremely low, and that it was impossible to isolate them from natural noises in amplitude-time diagrams.

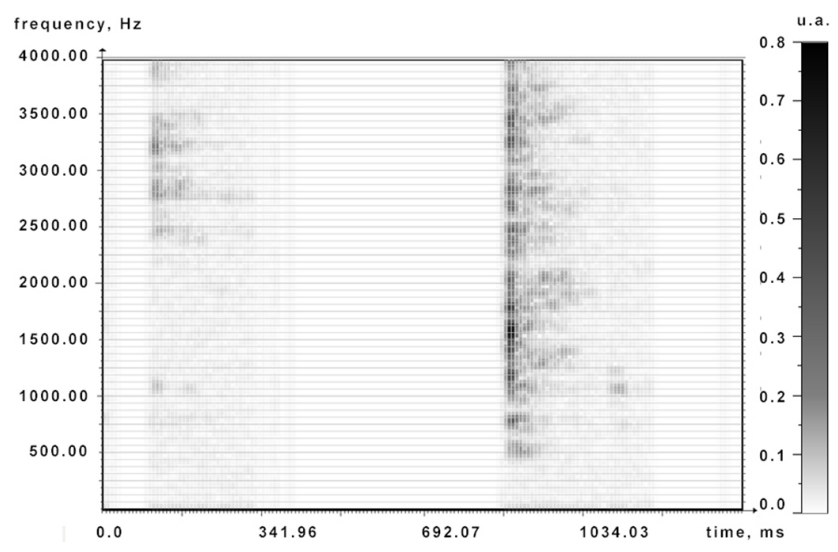

Figure 8. An EM signal registered during the granite sample fracturing.

It was observed that the EM emission undergoes changes during the rock rubbing procedure. First impulses were similar to the one depicted in Fig. 9b, and they were located throughout the entire frequency band of interest. Most of the emission energy lays in the $0.75-10 \mathrm{kHz}$ area. The following signals were similar to those that accompanied fracturing (Fig. 8) and had the noise-like behavior. Through the rubbing procedure, the granite and granodiorite specimens generated mainly short impulses within a broad frequency band. Rubbing two shale plates caused less intensive EM emissions and mostly noise-like signals. This appears to be due to relatively flat and smooth friction surfaces.

Seven out of nine sample pairs generated observable EM radiation against natural noises. In general, samples with the largest surface irregularities were characterized by strong EM emissions and short impulses, the number of which was higher than in the case of smooth rock surfaces.

\section{Discussion}

The results of the laboratory experiments demonstrate that EM emission is generated within a broad frequency band as a result of gradual loading of rock samples, including their fracturing, impacts and friction effect. Impulses generated by different types of mechanical actions can have some similarities. As a rule, all signals are characterized by a steep increase in intensity at the moment of the hit or the crack formation caused by gradual loading. Maximum amplitudes were located mainly in the $0-9 \mathrm{kHz}$ range. The exception is quartz - in some cases the maximums were in the higherfrequency area. The analysis of the recordings shows that harmonics of main signals are distinct in all cases. Nevertheless, in a few cases EM impulses generated by samples did not contain any observable harmonics. The maximum amplitude of signals, emitted by almost all rock specimens, fell on the second or third harmonics. 

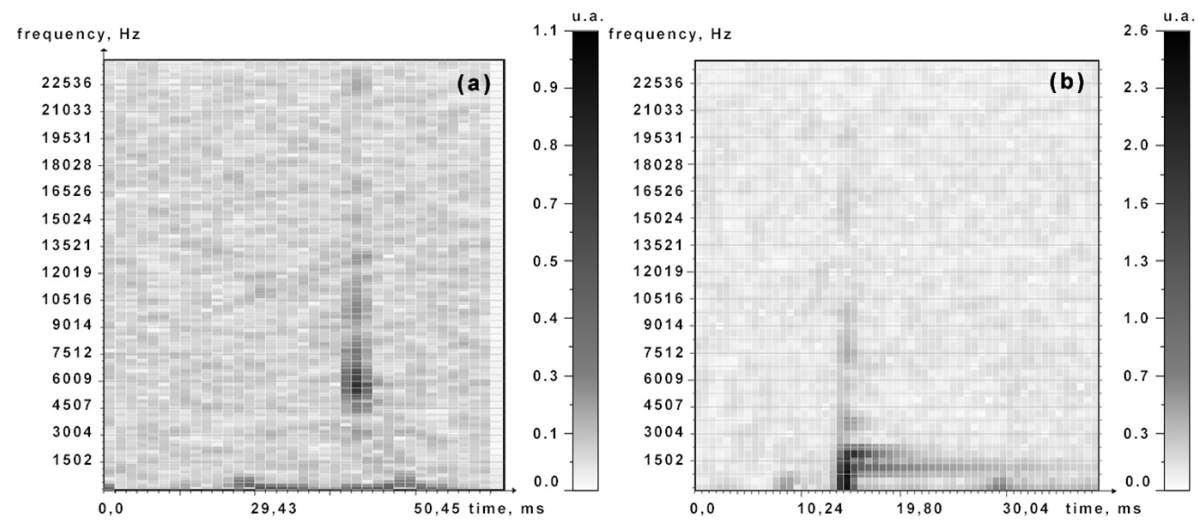

Figure 9. EM signals registered during rubbing of the (a) granite and the (b) granodiorite samples.

During the impact and gradual loading actions, relatively slow growth of EM fields took place prior to strong impulses. In the case of impact action, this can be due to the approaching of a metal ball to a sample's surface before the hit. Through gradual loading a slow growing pressure leads to the microcrack formation (at that moment we observe a weak and quite short EM signal). Then follows an avalanche-like breakdown of sample structures accompanied by the formation of large cracks (a sharp increase in EM field intensity).

The appearance of a series of repetitive weak peaks (Fig. 6) of certain frequencies, before and after EM impulse emission and during sample fracturing, still remains unexplained. It could have been the result of fracturing that follows large crack formation, but it is obvious that the formation of new cracks with equal periods of time is improbable.

All EM impulses, except the weakest ones, were accompanied by relatively strong acoustic signals during gradual loading.

It was discovered that a greater number of impacts results in a change in the EM emission spectrum and a decrease in impulse intensity during the experiment. We need to mention that after $24 \mathrm{~h}$ of standstill, the intensity of signals increases, but it does not exceed $50 \%$ of its value at the beginning of the experiment. Then, with the growing number of hits, the level of signals decreases, but not as rapidly as at the beginning of the experiment.

The EM emission caused by the fractioning process was weak but still perceptible among the natural noises.

The information about the spectral composition of the EM emissions that appeared during different mechanical actions on the rock samples demonstrates to us that the main level of radiation lies in the $0-10 \mathrm{kHz}$ band.

\section{Conclusions}

According to the findings, dissimilar EM signals can be generated as a result of different mechanical actions on rock samples of one type. It is shown that EM signals are characterized by a different number of impulses and spectral compositions, depending on the specimen dimensions of the same rock species, during the gradual loading.

The experiment on the impact action was held in two stages. It was observed that in the beginning of the second stage, the level of the EM emission was two times lower than at the start of the experiment, and it was fading slower. As the number of hits increased at the second stage, high-frequency components appeared in the spectrum, and their magnitudes lowered at the end of the experiment.

We can subdivide EM impulses that were observed during the fractioning process into two types: the first one is characteristic of hitting action - the impulse that is followed by a $10-30 \mathrm{~m}$ lasting emission in a narrow-frequency band; and the second one is a noise-like signal, typical of gradual loading action.

The results of spectral and spectral-temporal analysis served for us as a basis to select a frequency range where the most intensive EM emissions were generated by all rock samples during different types of mechanical actions.

Acknowledgements. The author would like to thank the editor and referees for their useful comments and constructive suggestions that helped to improve the manuscript.

Edited by: F. Masci

Reviewed by: four anonymous referees

\section{References}

Anastasiadis, C., Triantis, D., and Hogarth, C. A.: Comments on the phenomena underlying pressure stimulated currents (PSC) in dielectric rock materials, J. Mater. Sci., 42, 2538-2542, 2007.

Carpinteri, A., Lacidogna, G., Borla, O., Manuello, A., and Niccolini, G.: Electromagnetic and neutron emissions from brittle rocks failure: Experimental evidence and geological implications, Sadhana, Vol. 37, Part 1, 59-78, 2012.

Eftaxias, K., Kapiris, P., Polygiannakis, J., Peratzakis, A., Kopanas, J., Antonopoulos, G., and Rigas, D.: Experience of 
short term earthquake precursors with VLF-VHF electromagnetic emissions, Nat. Hazards Earth Syst. Sci., 3, 217-228, doi:10.5194/nhess-3-217-2003, 2003.

Freund, F. T.: Pre-earthquake signals - Part I: Deviatoric stresses turn rocks into a source of electric currents, Nat. Hazards Earth Syst. Sci., 7, 535-541, doi:10.5194/nhess-7-535-2007, 2007.

Hayakawa, M.: Atmospheric and ionospheric electromagnetic phenomena associated with earthquakes, Terra Sci. Pub. Co., 1990.

Hayakawa, M. and Fujinawa, Y.: Electromagnetic phenomena related to earthquake prediction, Terra Sci. Pub. Co., 1994.

Hayakawa, M., Gotoh, T., and Ikeda, M.: A network of reception of over-horizon VHF signals associated with earthquakes and some preliminary results, Journal of Atmospheric Electricity, 25, 1928, 2005.

Ida, Y., Yang, D., Li, Q., Sun, H., and Hayakawa, M.: Detection of ULF electromagnetic emissions as a precursor to an earthquake in China with an improved polarization analysis, Nat. Hazards Earth Syst. Sci., 8, 775-777, doi:10.5194/nhess-8-7752008, 2008.

Ishido, T. and Mizutani, H.: Experimental and theoretical basis of electrokinetic phenomena in rock-water systems and its applications to geophysics, J. Geophys. Res., 86, 1763-1775, 1981.

Kopytenko, Y. A., Matiashvili, T. G., Voronov, P. M., Kopytenko, E. A., and Molchanov, O. A.: Ultra low frequency emission associated with Spitak earthquake and following aftershock activity using geomagnetic pulsation data at observatories Dusheti and Vardziya, Preprint of IZMIRAN, Vol. 3, 888, 1990.

Kyriazis, P., Anastasiadis, C., Triantis, D., and Vallianatos, F.: Wavelet analysis on pressure stimulated currents emitted by marble samples, Nat. Hazards Earth Syst. Sci., 6, 889-894, doi:10.5194/nhess-6-889-2006, 2006.

Liu, J. Y., Chuo, Y. J., Shan, S. J., Tsai, Y. B., Chen, Y. I., Pulinets, S. A., and Yu, S. B.: Pre-earthquake ionospheric anomalies registered by continuous GPS TEC measurements, Ann. Geophys., 22, 1585-1593, doi:10.5194/angeo-22-1585-2004, 2004.

Lsaev, N., Serebrrakova, O., and Teodosiev, D.: Electromagnetic and plasma effects of the seismological activity in the Earth ionosphere, Bulgarian J. Physics, 27, 43-46, 2000.

Masci, F.: On the ULF magnetic ratio increase before the 2008 Iwate-Miyagi Nairiku earthquake by Hirano and Hattori (2011), J. Asian Earth Sci., 56, 258-262, 2012a.

Masci, F.: Comment on "Ultra Low Frequency (ULF) European multi station magnetic field analysis before and during the 2009 earthquake at L'Aquila regarding regional geotechnical information" by Prattes et al. (2011), Nat. Hazards Earth Syst. Sci., 12, 1717-1719, doi:10.5194/nhess-12-1717-2012, 2012 b.

Masci, F. and Thomas, J. N.: Comment on "Fractal analysis of ULF electromagnetic emissions in possible association with earthquakes in China" by Ida et al. (2012), Nonlinear Proc. Geoph., 20, 417-421, 2013.

Mognaschi, E. R.: On the possible origin, propagation and detectability of electromagnetic precursors of earthquakes, Atti Ticinensi di Scienze della Terra, 43, 111-118, 2002
Molchanov, O. A., Kopytenko, Y. A., Voronov, P. M., Kopytenko, E. A., Matiashvili, T. G., Freser-Smith, A. C., and Bernardi, A.: Results of ULF magnetic field measurements near the epicenters of the Spitaka $(\mathrm{Ms}=6.9)$ and Loma Prieta $(\mathrm{Ms}=7.1)$ earthquakes: comparative analysis, Geophys. Res. Lett., 19, 1495-1498, 1992.

Nardi, A. and Caputo, M.: Monitoring the mechanical stress of rocks through the electromagnetic emission produced by fracturing, Elsevier, International Journal of Rock Mechanics \& Mining Science, 46, 940-945, 2009.

Nitsan, U.: Electromagnetic emission accompanying fracture of quartz-bearing rocks, Geophys. Res. Lett., 4, 333-337, 1977.

Nomikos, K., Vallianatos, F., Kaliakatsos, J., Sideris, S., and Bakatsakis, M.: Latest aspects of telluric and electromagnetic variations associated with shallow and intermediate depth earthquakes in South Aegean, Annali di Geofisica, XL, 2, 361-374, 1997.

Ogawa, T. and Utada, H.: Electromagnetic signals related to incidence of a teleseismic body wave into a subsurface piezoelectric body, Earth Planets Space, 52, 253-260, 2000.

Rabinovitch, A., Frid, V., and Bahat, D.: Parametrization of electromagnetic radiation pulses obtained by triaxial fracture of granite samples, Phil. Mag. Lett., 77, 289-293, 1998.

Rapoport, Y., Grimalsky, M., Hayakawa, M., Ivchenko, V., JuarezR, D., Koshevaya, S., and Gotynyan, O.: Change of ionospheric plasma parameters under the influence of electric field which has lithospheric origin and due to random emanation, Phys. Chem. Earth, 29, 579-587, 2004.

Stavrakas, I., Triantis, D., Agioutantis, Z., Maurigiannakis, S., Saltas, V., Vallianatos, F., and Clarke, M.: Pressure stimulated currents in rocks and their correlation with mechanical properties, Nat. Hazards Earth Syst. Sci., 4, 563-567, doi:10.5194/nhess-4-563-2004, 2004.

Triantis, D., Anastasiadis, C., Vallianatos, F., Kyriazis, P., and Nover, G.: Electric signal emissions during repeated abrupt uniaxial compressional stress steps in amphibolite from KTB drilling, Nat. Hazards Earth Syst. Sci., 7, 149-154, doi:10.5194/nhess-7-149-2007, 2007.

Tzanis, A. and Vallianatos, F.: A critical review of ULF electric earthquake precursors, Annali di Geofisica, 44/2, 429-460, 2001.

Tzanis, A., Vallianatos, F., and Gruszow, S.: Identification and discrimination of transient electric earthquake precursors: Fact, fiction and some possibilities, Phys. Eart Planet. Int., 121, 223-248, 2000.

Vallianatos, F. and Tzanis, A.: Electric current generation associated with the deformation rate of a solid: Preseismic and coseismic signals, Phys. Chem. Earth, 23, 933-939, 1998.

Yasuhiko, M., Yoshihiko, O., and Josef, S.: Acoustic and electromagnetic emission from crack created in rock sample under deformation, available at: www.ndt.net/article/jae/papers/27-157. pdf (last access: 3 April 2014), 2009. 